\title{
STRATEGI PSIKOLOGI MEREKRUT PEMIKIRAN MUSLIM DALAM MAJALAH DABIQ
}

\author{
Noor Izatie Che Zawawi, Zul'Azmi Yaakob, dan Nur Farhana Abdul Rahman \\ Fakulti Pengajian Islam, Universiti Kebangsaan Malaysia \\ noorizatie92@gmail.com
}

Diterima 15 September 2017 | Direview 27 Juli 2018 | Diterbitkan 31 Desember 2018

\begin{abstract}
:
The emergence of more propaganda magazine because of propagandas or strategies development to spread the ideology of Islamic extremist groups.Dabiq magazines appear as a result of the development of the propagandas of militan Islamic State (IS), which has its own narratives to spread its ideology and attrack people around the world to join their jihad. This paper focuses on the narratives of psychological strategies by IS contained in the Dabiq magazine in recruiting people's mind to join the Khilafah.
\end{abstract}

Keywords: Jihad, propagandas, Dabiq, narratives

\begin{abstract}
Abstrak:
Munculnya lebih banyak majalah propaganda karena propaganda atau pengembangan strategi untuk menyebarkan ideologi kelompok-kelompok ekstremis Islam. Majalah-majalah DMAB muncul sebagai hasil pengembangan propaganda militan Negara Islam (IS), yang memiliki narasi sendiri untuk menyebarkan ideologinya. dan attrack orang-orang di selurub dunia untuke bergabung dengan jihad mereka. Makalah ini berfokus pada narasi strategi psikologis oleh IS yang terdapat dalam majalah Dabiq dalam merekrut pikiran orang untuk bergabung dengan Khilafah.
\end{abstract}

Kata kunci: Jihad, propaganda, Dabiq, narasi

\section{Pendahuluan}

Kebelakangan ini banyak majalah propaganda yang dikeluarkan oleh golongan pelampau atau teroris agama yang berjuang atas nama jihad. Sebagai contoh majalah Inspire yang dikeluarkan oleh Media Foundation of al-Malahem milik kumpulan al-Qaeda yang diedit oleh Samir Khan ${ }^{1}$, majalah Kabdat Allab

\footnotetext{
${ }^{1}$ Aaron Y. Zelin, “Inspire Magazine,” n.d., http://jihadology.net/category/inspire-magazine/.
} 
(The Fist of God) oleh Hizbullah ${ }^{2}$, majalah al-Waie oleh Hizb al-Tahrir dan majalah Dabiq oleh al-Hayat Media Center milik Islamic State (IS).

Penelitian ini berfokus pada narasi strategi psikologis oleh IS yang terdapat dalam majalah Dabiq dalam merekrut pikiran orang untuk bergabung dengan Khilafah. Kesemua majalah propaganda mempunyai naratifnya diselitkan secara langsung. Naratif ialah cerita atau kisah tentang peristiwa dan pengalaman. ${ }^{3}$ Naratif juga adalah proses penceritaan (story telling) yang membolehkan pendengar mempercayai sesuatu cerita yang dinyatakan oleh mana-mana pihak. ${ }^{4}$ Sebagai contoh naratifyang digunakan oleh militan IS adalah konsep jihad sebagai satu kewajiban agama yang mesti dilaksanakan oleh setiap individu Islam, imej pejuang keadilan kepada umat Islam yang tertindas di seluruh dunia, kisah-kisah pejuang IS yang didakwa mati syahid dan banyak lagi. ${ }^{5}$ Naratif-naratif ini menunjukkan kekuatan kuasa kumpulan IS dalam menyatukan umat Islam daripada seluruh dunia dan boleh menaikkansentimen umat Islam untuk bersimpati serta menyokongperjuangan mereka. Namun, naratif-naratif ini merupakan naratif psikologi yang dijadikan strategi oleh kumpulan IS dalam merekrut pemikiran orang ramai untuk menyertai Khilafah.

\section{Strategi Psikologi Merekrut Pemikiran Muslim dalam Majalah Dabiq}

Kemunculan majalah Dabiq oleh kumpulan IS membawa pelbagai naratif di dalam kandungan majalah tersebut bagi menarik minat pembaca untuk menghayati mesej yang ingin disampaikan. Antara naratif tersebut adalah konsep jihad sebagai satu kewajiban agama dan mesti dilaksanakan oleh setiap orang Islam termasuklah wanita dan berlainan bangsa.Seruan supaya melaksanakan hijrah ke negara Islam ditekankan agar semua orang Islam yang beriman dapat bersatu, saling menyayangi, menjaga dan berkorban antara satu sama lain demi menegakkan agama Allah. ${ }^{6}$ Jihad IS adalah berkisar mengenai hijrah, memberikan taat setia kepada Khilafah, sam' (mendengar), ketaatan kepada Allah dan i'dad (latihan) yang membawa kepada ribat serta qital

\footnotetext{
${ }^{2}$ Hezbollah, n.d., http://www.worldwizzy.com/library/Hezbollah\#Media_operations.

${ }^{3}$ Kamus Dewan., keempat. (Kuala Lumpur: Dewan Bahasa dan Pustaka, 2007).

4 Zulkarnain Haron, "Melawan Naratif-Naratif IS/ISIS/DAESH,"Berita Tentera Darat Malaysia," n.d., https://btdmonline.net/2016/03/melawan-naratif-naratif-islamic-state-di-iraqdan-syria-isis-a-k-a-ad-dawla-al-islmiyya-fi-iraq-wa-ash-sham-daesh-apa-yang-perlu-andaketahui-dan-bagaimana-melawan-naratif-naratif-tersebut/.

5 Zulkarnain Haron, “Islamic State (IS) Soalan-Soalan Lazim."Berita Tentera Darat Malaysia," 2016, https://btdmonline.net/archive/btdm205/mobile/index.html\#p=1.

${ }^{6}$ Ibid.
} 
(pertempuran) kemudian Khilafah atau shahadah. ${ }^{7}$ Jihad ini adalah asas untuk seseorang berubah dan melaksanakan perintah Allah supaya menentang golongan yang mengabaikan Islam seperti firman Allah dalam surah al-Anfal: 39 yang bermaksud:

"Perangilah mereka sehingga tidak ada lagi fitnah dan (sehingga) menjadilah agama itu selurubnya (bebas) bagi Allah semata-mata."

IS bukan sahaja memerangi golongan non-Muslim, malah terhadap masyarakat Islam itu sendiri kerana didakwa menjadi 'tali barut' Barat dan golongan 'kafir' menurut kebekuan ijtihad mereka. ${ }^{8}$ IS menunjukkan imej yang baik di negara Islam dengan semua orang bersatu menegakkan agama Islam dan memerangi golongan kafir. Hal ini adalah strategi psikologi IS supaya pembaca terkesan dengan jihadnya dan memberikan taat setia kepada Khilafah. Naratif yang dipaparkan seolah-olah IS mendakwa jihad menurut perspektif Islam hanyalah terdapat jihad qital yang memerangi golongan kafir dan golongan Islam yang didakwa berkerjasama dengan kafir semata-mata. Bahkan di dalam Islam, jihad mempunyai pelbagai kategori seperti jihad dengan lisan iaitu berdakwah mengenai ajaran Islam kepada masyarakat, jihad dengan harta iaitu menginfakkan harta kekayaan di jalan Allah dan jihad dengan jiwa atau qital iaitu memerangi orang kafir yang memerangi Islam dan umat Islam. ${ }^{9}$ Namun, Allah memerintahkan berperang hanya dalam situasi tertentu sahaja. Pertama adalah ketika kaum Muslim atau negeri mereka diserang oleh orangorang kafir seperti firman Allah dalam surah al-Baqarah: 190 yang bermaksud:

"Dan perangilah di jalan Allah orang-orang yang memerangi kamu, (tetapi) janganlah kamu melampaui batas kerana sesunggubnya Allah tidak menyukai orang-orang yang melampani batas."

Kedua adalah ketika terdapat sekelompok komuniti Muslim yang diperangi oleh orang-orang atau negara kafir seperti firman Allah dalam surah al-Anfal: 72 yang bermaksud:

\footnotetext{
${ }^{7}$ Ibid.

8 Zul'Azmi Yaakob \& Ahmad Sunawari Long, "Terorisme Sebagai Cabaran Ideologi Muslim Masa Kini: Satu Analisis Dari Perspektif Falsafah,” International Journal of Islamic Thought (n.d.).

${ }^{9}$ Ahmad Dzikran, Mati Syabid (Kuala Lumpur: Al-Mihrab Publications Sdn, n.d.).
} 
"Jika mereka meminta pertolongan kepada kamu dalam perkara menentang musub untuk membela agama, maka wajiblah kamu menolongnya, kecuali terbadap kaum yang ada perjanjian setia di antara kamu dengan mereka."

Ketiga adalah ketika dakwah Islam yang dilakukan oleh negara Islam dihalang oleh pemerintah kafir dengan kekuatan fizikal mereka seperti firman Allah dalam surah al-Baqarah: 193 yang bermaksud:

"Dan perangilah mereka itu, sehingga tidak ada fitnah lagi dan (sehingga) ketaatan itu hanya semata-mata untuk. Allah.Jika mereka berhenti (dari memusubi kamu), maka tidak ada permusuban (lagi), kecuali terbadap orang-orang yang zalim."10

Namun, tidak semua orang kafir boleh dibunuh. Terdapat ancaman yang keras sekiranya membunuh ketiga-tiga jenis orang kafir dalam sabda Rasulullah SAW daripada Abdullah bin 'Amr:

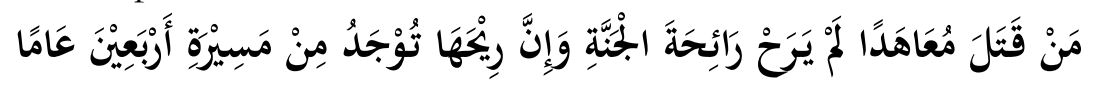

"Sesiapa yang membunub kafir mu'ahaddia tidak akan mencium bau syurga dan sesungguhnya bau syurga itu tercium dari perjalanan empat puluh tabun." (Riwayat Bukhari No. 3166).

Ibnu Hajar ra berpendapat bahawa kata mu'ahad dalam hadis tersebut mempunyai skop yang luas. Beliau berkata, "Dan yang dimaksudkan dengan mu'ahad adalab setiap yang mempunyai perjanjian dengan kaum Muslimin, baik dengan akad jisyah (kafir zimmi), perjanjian daripada penguasa (kafir mu'ahad) atau jaminan keamanan daripada seorang Muslim (kafir musta'man)."

Manakala orang kafir yang dibolehkan membunuhnya ialah kafir harbi iaitu orang kafir yang memerangi kaum Muslimin.

Lagipun, militan IS tidak boleh membunuh orang Muslim sesuka hati kerana betapa terhormatnya nyawa seorang Muslim dan Allah menyediakan azab yang besar ke atas pembunuh orang Muslim. Sebagaimana firman Allah dalam surah al-Nisa': 93 yang bermaksud:

"Dan sesiapa yang membunuh seorang mukmin dengan sengaja maka balasannya ialah Neraka Jahanam, kekal dia di dalamnya dan Allah murka kepadanya dan melaknatnya serta menyediakan azab seksa yang besar baginya."

10 Ibid. 
Diriwayatkan oleh Abdullah bin 'Amr bahawa Rasulullah SAW juga menegaskan:

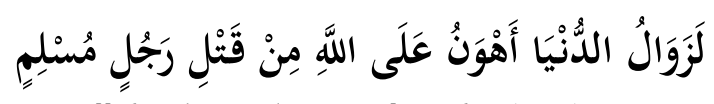

"Hilangnya dunia lebih ringan di sisi Allah daripada membunub (jiwa) seorang Muslim.”(Sunan at-Tirmizi, 1421).

Di samping itu, strategi psikologi juga ditunjukkan melalui naratif mengenai pandangan orang Islam yang sedang tertindas di negara lain di dunia dan setiap individu mempunyai tanggungjawab untuk melindungi saudara seagama. ${ }^{12}$ Keadaan ini seolah-olah memerlukan satu gerakan yang melawan golongan yang menindas umat Islam di negara lain. Oleh itu, pejuang-pejuang militan IS tampil sebagai penyelamat keadilan menggunakan kekerasan dan respon dalam melawan golongan kuffar. Sebagai contoh majalah Dabiq edisi yang ke-7menyatakan serangan terhadap gereja Katolik di Baghdad adalah untuk membalas dendam bagi penganiayaan wanita Muslim iaitu Kamilia Shehata, Wafa Constantine dan wanita lain yang telah diseksa dan dibunuh. Serangan lima istishhadiyyin tersebut membunuh dan mencederakan lebih daripada 100 orang yang dianggap sebagai tentera salib. Walaupun serangan yang dilakukan adalah tindakan yang ganas pada keseluruhannya tetapi militan IS memanipulasi persepsi masyarakat seluruh dunia bahawa tindakan tersebut setimpal dengan perbuatan gereja terhadap wanita Muslim di sana. Menurut kumpulan IS, setiap individu bertanggungjawab untuk melindungi dan membalas kembali di atas perbuatan tersebut. Di dalam Islam, tindakan melindungi saudara sesama Islam adalah sesuatu tindakan yang mulia.Namun, tindakan keganasan menyerang balik musuh tidak boleh dilakukan. Matlamat yang baik untuk membantu tidak semestinya menghalalkan cara yang ganas dan menzalimi orang lain. Sebagaimana firman Allah dalam surah al-Shuraa: 39-43 yang bermaksud:

"39. Dan juga (lebih baik dan lebih kekeal bagi) orang-orangyang apabila ditimpa sesuatu perbuatan secara zalim, mereka hanya bertindak membeladiri (sepadan dan tidak melampaui batas). 40. Dan (jika kamu bendak membalas maka) balasan sesuatu kejabatan ialah kejabatan yang bersamaan dengannya; dalam pada itu sesiapa yang

\footnotetext{
${ }_{11}$ Mohammad Isa bin Surah At-Tirmizi, Tarjamah Sunan At-Tirmidæi (Kuala Lumpur: Victory Agencie, 1993).

12 Zeiger, Sara, Bagaimana Untuk. Menjejaskan Naratif Ekstremis Ganas Di Asia Tenggara (Jakarta: Iman Badwan, 2016).
} 
memaafkan (kejabatan orang) dan berbuat baik (kepadanya), maka pahalanya tetap dijamin oleh Allah (dengan diberi balasan yang sebaik-baiknya). Sesunggubnya Allah tidak suka kepada orang-orang yang berlaku zalim. 41. Dan sesunggubnya orang yang bertindak membela diri setelah dia diralimi, maka mereka yang demikian keadaannya, tidak ada sebarang jalan bendak menyalabkan mereka. 42. Sesunggubnya jalan (untuk menyalabkan) banyalah terbadap orang-orang yang melakukan kezaliman kepada manusia dan bermaharajalela di muka bumi dengan tiada sebarang alasan yang benar. Mereka itulah orang-orang yang peroleh azab seksa yang tidak terperi sakitnya. 43. Dalam pada itu (ingatlah), orang yang bersabar dan memaafkan (kesalaban orang terbadapnya), sesunggubnya yang demikian itu adalah dari perkara-perkara yang mulia (melakukannya)."

Tambahan pula, etika peperangan di dalam Islam juga melarang meruntuhkan atau menceroboh rumah ibadat agama lain walaupun di dalam peperangan. Allah mengutuk orang yang menzalimi orang lain. Seperti firman Allah dalam surah al-Hajj:40 yang bermaksud:

"Kalaulah Allah tidak menolak setengah manusia menentang pencerobohan setengahnya yang lain, nescay a runtublah tempat-tempat pertapaan serta gereja-gereja (kaum Nasrani) dan tempat-tempat sembahyang (kaum Yahudi) dan juga masjid-masjid (orang Islam) yang di dalamnya banyak disebut nama Allah."13

Menurut Imam al-Qurtubi, ayat itu cukup jelas menegaskan syariat yang ditetapkan oleh Allah di muka bumi supaya melindungi tempat ibadat itu daripada keganasan tangan-tangan yang tidak bertanggungjawab. Rasulullah SAW tidak henti-henti menekankan agar hak Nasrani dan Yahudi atau bukan Muslim yang lainsupaya diberikan secara adil dan seimbang. Hal itu terbukti ketika Rasulullah SAW memberikan kesempatan kepada para pendeta Bani alHarits dan Najran untuk tetap bebas beribadat. Ketika Umar bin Khattab merebut Jerussalam, dia menjamin hak beribadat kaum Nasrani dan berjanji tidak akan memusnahkan gereja mereka. Semua ini adalah bukti bahawa Islam menolak pelbagai bentuk kerosakan terhadap tempat ibadat dan melakukan keganasan terhadap para penganut agama lain.

Selain itu, setiap edisi majalah Dabiq diselitkan dengan naratif psikologi melalui penceritaan pengalaman individu yang memberikan taat setia kepada kumpulan IS dan kisah mujahid yang didakwamati syahid. Naratif sebegini secara langsung memberi inspirasi, motivasi dan dijadikan idola kepada

${ }^{13}$ Ahmad Dzikran, Mati Syahid. 
masyarakat terutama individu yang selama kehidupannya melakukan banyak kemungkaran dan kemaksiatan. Dengan memberikan taat setia dan menyertai jihad militan IS melawan golongan kuffar, dosa yang terdahulu yang dilakukan oleh seseorang individu akan dimaafkan oleh Allah. Tanggapan seumpama ini diterapkan di dalam pemikiran seluruh masyarakat di dunia menjadi faktor penarik untuk menyertai jihad militan IS. Semua ini diceritakan di dalam pendahuluan majalah Dabiq edisi ke-13:

Thus, the believers who do trade with Allah will never lose, rather, the only stand to profit. $\{O$ you who have believed, shall I guide you to a transaction that will save you from a painful punishment? It is that you believe in Allah and His Messengerand strive in the cause of Allah with your wealth and your lives. That is best for you, if you should know. He will forgive for you your sins and admit you to gardens beneath which rivers flow and pleasant dwellings in gardens of perpetual residence. That is the great attainment $\}$ [As-Saff: 10-12]. ${ }^{14}$

Hal ini terjadi disebabkan wujud kelompok masyarakat yang jahil mengenai Islam. Penceritaan sebegini berjaya menarik perhatian golongan belia yang mencari jalan pintas ke syurga. Jalan ini dimanipulasi oleh kumpulan atas nama jihad sebagai jalan pengampunan dosa-dosa. Namun persoalan muncul adakah pejuang-pejuang IS ini sememangnya mati syahid? Adakah pejuangpejuang tersebut melakukan jihad mengikut syariat Islam yang sebetulnya sehingga didakwa telah mati syahid? Mati syahid ialah seorang Muslim yang meninggal ketika berperang atau mati $f i$ sabilillah atau berjuang di jalan Allah membela kebenaran dan mempertahankan hak dengan penuh kesabaran serta keikhlasan untuk menegakkanagama Allah. ${ }^{15}$ Walau bagaimanapun, terdapat etika dan peraturan yang ditetapkan oleh Islam ketika berjihad yang perlu dipatuhi oleh mujahid sebenar untuk memperoleh ganjaran syahid. Antaranya ialah menghormati mayat musuh, tidak melakukan penyeksaan atau penderaan terhadap musuh, tidak menyerang orang awam dan orang yang tidak bersalah, memberi bantuan kemanusiaan kepada musuh, melayani musuh dengan belas kasihan dan sebagainya ${ }^{16}$ Islam juga melarang membunuh utusan atau duta musuh, melarang membunuh kaum wanita, anak-anak, orang gila, orang tua, pendeta, orang buta, orang sakit, makruh hukumnya jika merosakkan bangunan

\footnotetext{
14“'The Rafidah from Ibn Saba' to the Dajjal” (2016), hlm.4.

${ }^{15}$ Ahmad Dzikran, Mati Syabid.

${ }^{16}$ Hanif Yusabra Yusuf. Islamic State (IS):, Implikasi Kepada Keselamatan (MalaysiA: kertas kerja akademi, n.d.).
} 
dan tumbuh-tumbuhan serta haram membunuh haiwan tunggangan atau haiwan lain milik orang-orang kafir. ${ }^{17} \mathrm{Hal}$ ini jelas menunjukkan kumpulan IS telah melanggar etika jihad di dalam peperangan dan tidak mungkin diangkat sebagai mujahid. Sebagaimana di dalam Sahih Muslim diriwayatkan daripada Buraidah bahawa Rasulullah bersabda:

"Berperanglah dengan nama Allahuntuk menegakean di jalan Allah. Perangilah orang yang kafir kepada Allah.Berperanglah kamu danjangan menipu (dalam harta rampasan), jangan kamu mengkbianati janji, jangan membunuh dengan kejamdan jangan membunub kanak-kanak.".18

Lagipun, pengampunan dosa-dosa mempunyai pelbagai cara termasuklah melalui taubat nasuha. Setiap individu tidak semestinya perlu melibatkan diri di dalam aktiviti jihad terutamanya jihad yang dibawa oleh militan IS. Jalan pintas ke syurga tidak wujud melainkan memohon keampunan daripada Allah SWT.Menurut Islam, setiap kesalahan atau kemungkaran yang dilakukan hendaklah dihentikan segera dan bertaubat kepada Allah. Taubat menghapus dosa-dosa yang terdahulu.Allah mengampuni dosa orang-orang yang bertaubat meskipun sebanyak buih di lautan atau setinggi langit. Sebagaimana firman Allah dalam surah al-Zumar: 53 yang bermaksud:

"Katakanlah (wahai Mubammad): Wahai hamba-bambaKu yang telah melampani batas terhadap diri mereka sendiri (dengan perbuatan-perbuatan maksiat), janganlah kamu berputus asa dari rahmat Allah, kerana sesunggubnya Allah mengampunkan segala dosa; sesunggubnya Dialah jua Yang Maha Pengampun, lagi Maha Mengasihani."

Rasulullah bersabda:

"Jika kamu melakukan kesalahan sehingga kesalahan kamu setinggi langit, kemudian kamu bertaubat, nescaya Allah akan menerima taubat kamu". ${ }^{19}$

Menurut Hasan al-Bashri, taubat adalah seseorang hamba yang menyesal terhadapkesilapan lalu dan berazam tidak mengulanginya.Manakala menurut al-Kalbi, taubat adalah beristighfar dengan lidah, menyesal dengan hati serta menahan dengan badan untuk tidak melakukannnya lagi.

\footnotetext{
17 Muhammad Mustafa al-Zuhaily, Al-Mu'tamad Dalam Figh Maz̧hab Syafi'i (Kuala Lumpur, 2012).

${ }^{18}$ Musthafa Bugha, Mukhtasar Sahib Bukhari (Johor: Perniagaan Jahabersa, 2013).

${ }^{19}$ Yusuf Qaradhawi, Astaghfirullah “Ampunanmu Ya Allab Aku Harapkan”.Terj. Muhammad Zaini Yabya (Selangor: Syabab Book Link, 2012).
} 
Kesimpulannya, taubat adalah penyesalan dengan hati, istighfar dengan lisan, meninggalkan perbuatan dosa dengan anggota badan dan berjanji untuk tidak akan mengerjakan perbuatan dosa itu lagi. ${ }^{20}$ Selain itu, membaca doa dan zikir juga merupakan cara lain untuk memohon pengampunan dosa-dosa daripada Allah SWT. Menurut riwayat Imamal-Bukhari dari Syaddad bin Aus ra daripada Rasulullah SAW bahawa beliau bersabda: "Sesungguhnya istighfar yang paling baik adalah seseorang mengucapkan:

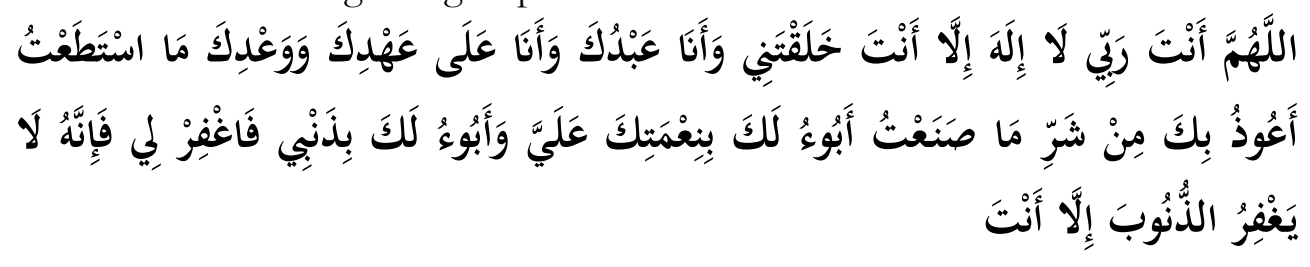

"Ya Allah, Engkau adalab Tubanku, tidak ada Tuban yang berbak diibadabi selain Engkau. Engkau telah menciptakanku dan aku adalah hamba-Mu.Aku menetapi perjanjian-Mu dan janji-Mu sesuai dengan kemampuanku.Aku berlindung kepada-Mu dari keburukan perbuatanku, aku mengakui dosaku kepada-Mu dan aku akui nikmatMu kepadaku, maka ampuni aku.Sebab tidak ada yang dapat mengampuni dosa selainMu."

Rasulullah SAW bersabda:

"Barangsiapa yang mengucapkannya pada waktu siang dengan penub keyakinan dan dia meninggal pada bari itu sebelum waktu petang, maka dia termasuk dari penghuni syurga. Barangsiapa yang mengucapkannya pada malam hari dengan penub keyakinan dan dia meninggal sebelum masuk. waktu pagi, maka dia termasuk dari pengbuni syurga."

Para ulama menghitung hadis ini sebagai satu riwayat untuk kedua-dua waktunya (malam dan pagi hari).Ini adalah salah satu zikir yang harus diucapkan pada waktu pagi (subuh) iaitu antara permulaan fajar dan terbitnya matahari serta di waktu petang. ${ }^{21}$ Syurga adalah jaminan baginya.Lafaz ini merupakan lafaz yang terbaik dan paling sempurna dalam memohon keampunan kepada Allah SWT. ${ }^{22}$

\footnotetext{
${ }^{20}$ Ibid.

${ }^{21}$ Musthafa Bugha, Mukhtasar Sabih Bukhari.

22 Abdur Razak bin Abdul Muhsin Al-Abbad, Cara Terbaik Dalam Memohon Ampunan, 2008, http://ebooks-

islam.fuwafuwa.info/\%5BAbdur $\% 20$ Razak $\% 20 \mathrm{Ibnu} \% 20 \mathrm{Abdul} \% 20 \mathrm{Muhsin} \% 20 \mathrm{AlAbbad} \% 5 \mathrm{D}$

\%20Cara\%20Terbaik\%20dalam\%20Memohon\%20Ampunan.pdf.
} 


\section{Simpulan}

Secara kesimpulannya, militan IS menggunakan pelbagai naratif bagi merekrut orang ramai menyertai Khilafah. Antaranya adalah naratif jihad sebagai satu kewajiban agama, sentimen umat Islam dihina, ditindas dan dijajah, Daulah Islam, Khilafah Islamiyah dan kisah pejuang-pejuang yang didakwa mati syahid dalam memperjuangkan jihad atas nama Islam. Kesemua naratif yang dipaparkan di dalam majalah Dabiq adalah strategi psikologi dalam menarik orang ramai bersimpati, bersatu dan menyertai perjuangannya menentang golongan kafir dan orang Islam yang didakwa bersubahat dengan golongan kafir di seluruh dunia. Naratif-naratif yang dipaparkan oleh militan IS sudah tentu mempunyai propaganda dan agendanya yang tersendiri dalam mempengaruhi pemikiran, emosi dan tindakan seseorang individu. Kita mesti sentiasa berhati-hati dan mempunyai pemikiran yang optimis agar tidak terpengaruh di dalam agenda tersebut.

\section{Daftar Pustaka}

Al-Abbad, Abdur Razak bin Abdul Muhsin. Cara Terbaik Dalam Memohon Ampunan, 2008. http://ebooksislam.fuwafuwa.info/ $\% 5 \mathrm{BAbdur} \% 20 \mathrm{Razak}^{2} \% 20 \mathrm{Ibnu} \% 20 \mathrm{Abdul} \% 20 \mathrm{Mu}$ hsin $\% 20$ AlAbbad $\% 5$ D \%20Cara $\% 20$ Terbaik\%20dalam\%20Memohon $\% 20$ Ampunan.pdf.

Bugha, Musthafa. Mukhtasar Sabih Bukhari. Johor: Perniagaan Jahabersa, 2013. Dzikran, Ahmad. Mati Syabid. Kuala Lumpur: Al-Mihrab Publications Sdn, n.d. Haron, Zulkarnain. "Islamic State (IS) Soalan-Soalan Lazim."Berita Tentera Darat Malaysia," 2016. https://btdmonline.net/archive/btdm205/mobile/index.html\#p=1. "Melawan Naratif-Naratif IS/ISIS/DAESH,"Berita Tentera Darat Malaysia," n.d. https://btdmonline.net/2016/03/melawan-naratifnaratif-islamic-state-di-iraq-dan-syria-isis-a-k-a-ad-dawla-al-islmiyya-fiiraq-wa-ash-sham-daesh-apa-yang-perlu-anda-ketahui-dan-bagaimanamelawan-naratif-naratif-tersebut/.

Hezbollah, n.d. http://www.worldwizzy.com/library/Hezbollah\#Media_operations. Kamus Dewan. Keempat. Kuala Lumpur: Dewan Bahasa dan Pustaka, 2007. Qaradhawi, Yusuf. Astaghfirullah “Ampunanmu Ya Allah Aku Harapkan”.Terj. Muhammad Zaini Yabya. Selangor: Syabab Book Link, 2012. 
Noor Izatie Che Zawawi, Zul'Azmi Yaakob, Nur Farhana Abdul R Strategi Psikologi 307

At-Tirmizi, Mohammad Isa bin Surah. Tarjamah Sunan At-Tirmidzi. Kuala Lumpur: Victory Agencie, 1993.

Yaakob, Zul'Azmi \& Ahmad Sunawari Long. "Terorisme Sebagai Cabaran Ideologi Muslim Masa Kini: Satu Analisis Dari Perspektif Falsafah.” International Journal of Islamic Thought (n.d.).

Yusuf, Hanif Yusabra. Islamic State (IS): Implikasi Kepada Keselamatan. MalaysiA: kertas kerja akademi, n.d.

Zeiger, Sara. Bagaimana Untuk Menjejaskan Naratif Ekstremis Ganas Di Asia Tenggara. Jakarta: Iman Badwan, 2016.

Al-Zuhaily, Muhammad Mustafa. Al-Mu'tamad Dalam Fiqh Mazhab Syafi'i. Kuala Lumpur, 2012. 
